\title{
Estimation of In-situ concrete strength using drilling resistance
}

\author{
Serkan Karatosun ${ }^{1}$, Muhammet Asan $^{2}$ and Oguz Gunes* \\ ${ }^{1}$ Istanbul Technical University, Department of Civil Engineering, 34467 Istanbul, Turkey \\ ${ }^{2}$ Gebze Technical University, Department of Civil Engineering, 41400 Gebze, Turkey
}

\begin{abstract}
Rapid and reliable condition assessment of reinforced concrete structures in high seismicity regions is a priority task in estimating their seismic safety. Non-destructive testing (NDT) methods may contribute to the condition assessment practice by providing fast and reliable strength estimation while causing minimal or no damage to the structure. Drilling resistance is an NDT method that has been used for mechanical characterization of natural stone and wood by measuring the force response for constant penetration rate and rotational speed. This paper focuses on the relationship between drilling resistance and compressive strength of concrete, including when it is combined with other NDT methods. Concrete cube samples produced using 6 different concrete mixtures were tested. Correlation equations were then obtained using statistical analysis. The results reveal that it may be possible to reliably estimate the compressive strength of concrete using drilling resistance method.
\end{abstract}

\section{Introduction}

Several major earthquakes and the resulting loss of life in the last decades drew attention to seismic safety of existing structures. Rapid and reliable condition assessment of structures in high seismicity regions is a priority task in estimating their seismic safety, especially when the quality of concrete is questionable. There are several test methods for in-situ strength assessment of reinforced concrete structures [1]. Testing samples cast concurrently during construction or cores drilled from the structure for compressive strength determination are the most frequently used conventional methods for estimating the strength of concrete in existing structures [2]. However, traditional methods have distinct drawbacks, for instance, results are not obtained rapidly, curing of concrete specimens may differ from that of the structure, and size and shape of concrete specimens may affect the strength properties [3]. Thus, many non-destructive testing (NDT) techniques have been developed to overcome these drawbacks. NDT techniques measure certain properties of concrete that can be indirectly related to strength and durability of structures. NDT methods may contribute to the condition assessment practice by providing fast and reliable strength estimation while causing minimal or no damage to the structure. The most commonly used NDT methods to estimate concrete strength are ultrasound pulse velocity (UPV) and Schmidt hammer [4].

In order to improve the reliability of assessment and the characterization of reinforced concrete structures, combining NDT methods is a strategy investigated by various researchers [5]. The main idea behind combining different NDT methods is the improvement of reliability through measurement of different unrelated characteristics that all relate to the compressive strength [6].

The primary objective of this study is to observe the relationship between drilling resistance and concrete strength, including when it is used in conjunction with other NDT methods. Statistical relationships were established between NDT results from Schmidt hammer, Silver-Schmidt hammer, ultrasonic pulse velocity and drilling resistance with those obtained from compressive strength tests. Single and multivariate regression relations were obtained for individual and combined use of NDT methods in relation to compressive strength test results.

\section{Concrete constituent and specimens}

A total of 17 concrete cube samples of $15 \mathrm{~cm}$ dimensions from 6 different concrete mixtures with the same maximum aggregate size $(12 \mathrm{~mm})$ were produced and tested in this study. All specimens were produced from the same constituent materials for consistency and were moist cured for 28 days after demoulding.

Table 1 presents the six different concrete mix proportions used in this study. The water to cement ratio by weight varied from 1.85 to 0.68 to vary the concrete strength. Compressive strengths of the tested concrete cube samples were in the range of $3.7 \mathrm{MPa}$ to $39 \mathrm{MPa}$ as shown in Table 1.

\section{Experimental work}

Four different NDT methods were used for this research, namely, Schmidt hammer, Silver-Schmidt hammer, 
Table 1. Mix proportions, densities of concrete mixtures and compressive strength test results.

\begin{tabular}{|c|c|c|c|c|c|c|c|}
\hline $\begin{array}{c}\text { Mix } \\
\text { No }\end{array}$ & $\begin{array}{c}\text { Cement } \\
\left(\mathrm{kg} / \mathrm{m}^{3}\right)\end{array}$ & W/C & $\begin{array}{c}\mathbf{N} . S^{a} \\
\left(\mathbf{k g} / \mathbf{m}^{3}\right)\end{array}$ & $\begin{array}{c}\text { C.S. }{ }^{\mathbf{b}} \\
\left(\mathbf{k g} / \mathbf{m}^{\mathbf{3}}\right)\end{array}$ & $\begin{array}{c}\text { C.S.1 } \\
\left(\mathbf{k g} / \mathbf{m}^{\mathbf{3}}\right)\end{array}$ & $\begin{array}{c}\text { Density }^{\mathrm{d}} \\
\left(\mathrm{kg} / \mathbf{m}^{3}\right)\end{array}$ & $\begin{array}{c}\left(\mathbf{f}_{\mathbf{c}}\right)^{\mathbf{d}} \\
(\mathrm{MPa})\end{array}$ \\
\hline 1 & 130 & 1.85 & 552 & 677 & 647 & 1967 & 3.8 \\
\hline 2 & 160 & 1.44 & 552 & 677 & 647 & 1979 & 6.9 \\
\hline 3 & 190 & 1.16 & 552 & 677 & 647 & 2074 & 13.8 \\
\hline 4 & 220 & 0.95 & 552 & 677 & 647 & 2091 & 15.2 \\
\hline 5 & 250 & 0.8 & 552 & 677 & 647 & 2116 & 23.9 \\
\hline 6 & 280 & 0.68 & 552 & 677 & 647 & 2192 & 38.8 \\
\hline
\end{tabular}

ultrasonic pulse velocity test and drilling resistance method. Results obtained from individual and combined use of these NDT methods were related to those obtained from uniaxial compressive strength tests.

\subsection{Compressive strength test}

The compression strength of concrete cube samples was obtained destructively using a concrete compression testing machine (Fig.1). The tests were performed according to EN 12390-3 [7].

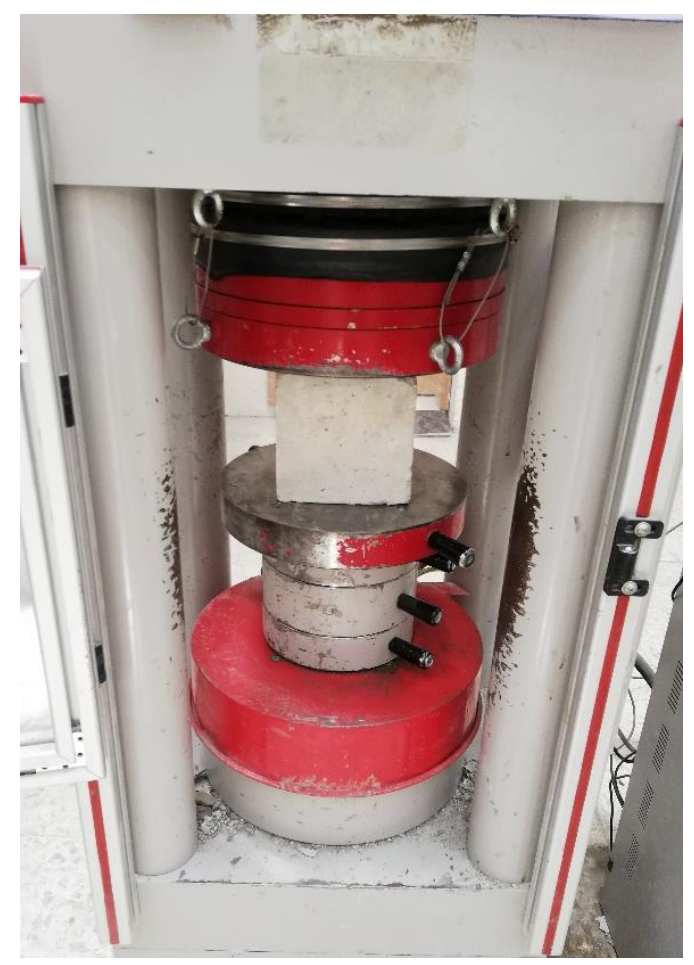

Fig. 1. Uniaxial Compressive strength test

\subsection{Schmidt hammer}

A Schmidt hammer, also known as rebound hammer is a device used to estimate the in-situ concrete strength in relation to surface hardness. Schmidt hammer is the most commonly used NDT technique to estimate concrete strength and its uniformity within a structure owing to its ease of use and low cost [8]. The Schmidt hammer basically measures the surface hardness from the rebound of a plunger that strikes the concrete surface (Fig. 2.a).
The test procedure was performed according to EN 12504-2 [9].

\subsection{Silver-Schmidt hammer}

In the traditional Schmidt hammer, the rebound number is obtained in relation to the distance the hammer mass compresses a spring upon impacting the concrete surface. Internal friction and the inclination are the major factors that influence the results [10]. The Silver-Schmidt hammer is a recently developed, more advanced device that measures the rebound number through an optical method in relation to the speed of hammer mass upon impact, which is almost unaffected by friction and inclination [11]. Thus, the results from this method are relatively less dispersed [10]. This test procedure was also performed according to EN 12504-2 [9].

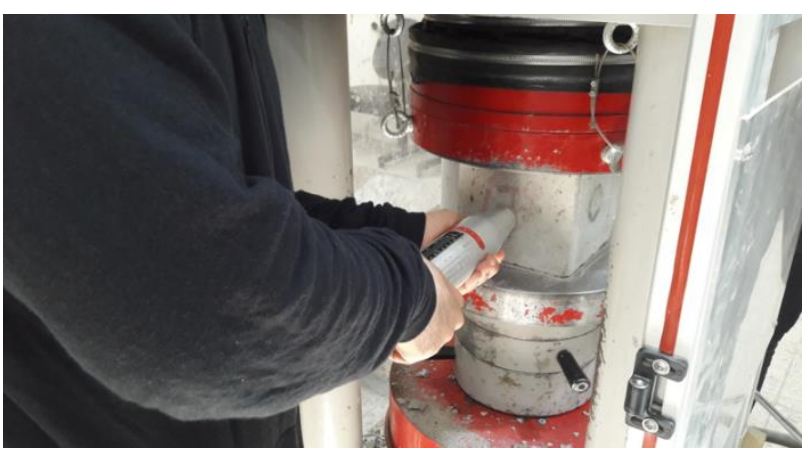

(a)

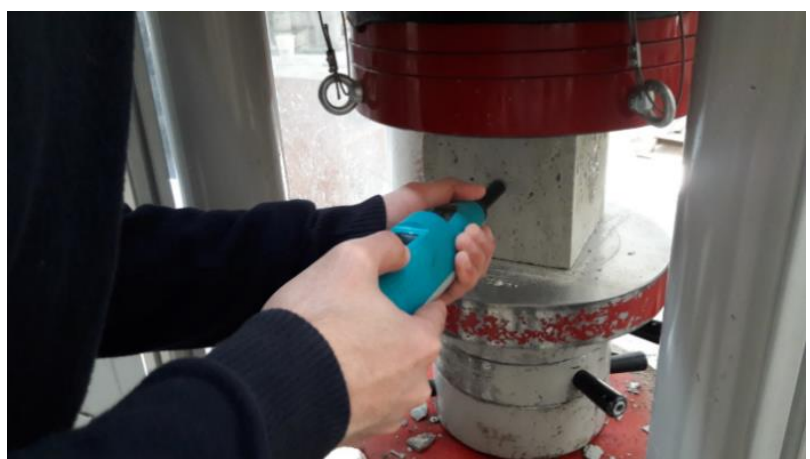

(b)

Fig. 2. Rebound hammer tests. (a) Standard Schmidt hammer, (b) Silver-Schmidt hammer 


\subsection{Ultrasonic pulse velocity}

The ultrasonic pulse velocity test has been used to determine the quality of the concrete since the 1960s [4]. This test can be carried out in direct, semi-direct or indirect fashion. In the direct method, the time of flight of ultrasound pressure waves travelling across the concrete cube specimen can be measured precisely (Fig. 3). Knowing the cube dimension, the ultrasonic pulse velocity (UPV) can be easily calculated. The test procedure was performed according to EN 12504-4 [12].

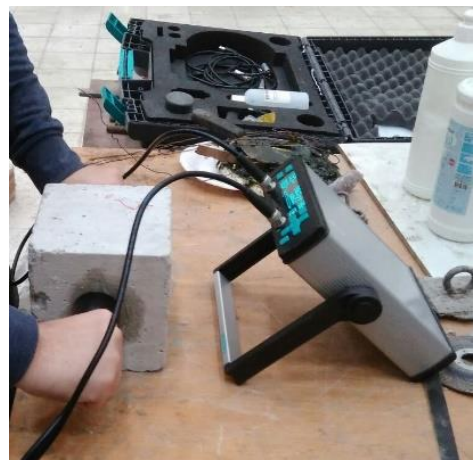

Fig. 3. Ultrasonic pulse velocity test

\subsection{Drilling resistance}

Drilling resistance is an NDT method that has been used for mechanical characterization of natural stone and wood. Although it is not yet a well-established and standardized non-destructive testing method, the drilling resistance test is considered to have a high potential for rapid and reliable estimation of in-situ concrete strength (Fig. 4).

This method simply involves estimation of concrete strength based on the resistance of drilling a hole inside concrete [13]. The time required to drill to a certain depth was measured while keeping the force and rotational speed constant. The constant force was achieved by placing the specimen setup on an electronic scale and adjusting the force to read an approximately constant weight on the scale. A powerful drill was used to ensure that the rotational speed is not affected by the concrete strength. To this effect, the constant rotational speed is an assumption, but even if it is violated in practice, it is a bias that is valid for all specimens of similar strength, which makes the correlations still valid but specific to the drill used. The relationship between drilling resistance expressed as the time to drill a unit depth $(\mathrm{s} / \mathrm{cm})$ and compressive strength was established through regression analysis. Since the drilling is performed to a certain depth in concrete, the method is less affected by carbonation and other factors such as fire damage $[14,15]$.

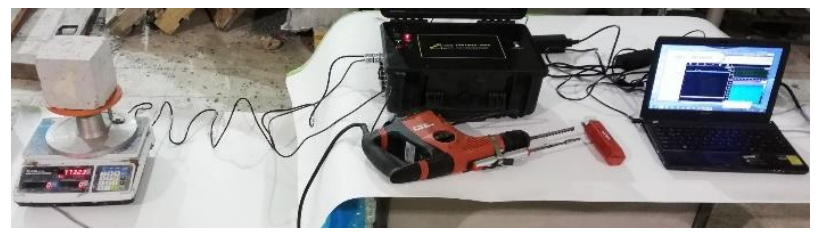

\section{Test results and discussions}

Four different NDT measurements were performed prior to compression tests on the specimens. Correlation relations were then derived through regression analysis on measured data from each NDT method in relation to the compression test results. These were compared with those based on the code equations in EN 13791 [16]. Additionally, multivariable regression analyses were performed by combining at least two NDT methods with the compression test. The correlation constants obtained for combined use of NDT methods gives an indication of whether the reliability is improved.

All correlation equations are compared with respect to the root mean square error (RMSE) and the coefficient of determination $\left(\mathrm{R}^{2}\right)$ as a means for reliability assessment.

\subsection{Univariate regressions}

In this section, correlation equations were obtained for the results of each NDT method in relation to destructive test (DT) results are presented. Table 2 provides these equations and the pertinent statistics. Plots of the correlation equations are provided in Figs. 5-9.

Table 2. Relationship between compressive strength and individual NDT results.

\begin{tabular}{lccc}
\hline Method & Model & $\mathbf{R}^{2}$ & RMSE $^{*}$ \\
\hline Rebound, R & $f_{c}=-33.5+1.80 \times R$ & 0.809 & 5.482 \\
Rebound,Q & $f_{c}=-28.0+1.40 \times Q$ & 0.940 & 3.085 \\
UPV & $f_{c}=-45.2+18.3 \times V$ & 0.820 & 5.326 \\
Drilling & $f_{c}=-31.1+35.4 \times D$ & 0.768 & 6.050 \\
Resistance,D & $f_{c}=0.002 \times R^{2.76}$ & 0.822 & 5.296 \\
Rebound, R & $f_{c}=0.001 \times Q^{2.80}$ & 0.970 & 2.190 \\
Rebound, Q & $f_{c}=0.040 \times V^{4.75}$ & 0.906 & 3.857 \\
UPV & $f_{c}=0.045$ & & \\
Drilling & $f_{c}=4.960 \times D^{3.41}$ & 0.906 & 5.120 \\
Resistance,D & & & \\
\hline
\end{tabular}

*Root Mean Square Error in unit of Mpa

Fig. 5 and Fig. 7 show the relationship between rebound numbers obtained from standard and Silver-Schmidt hammers, respectively, with the compressive strength test results. Both linear and non-linear relations in the form of power curves are shown in the figures. The coefficient of determination $\left(\mathrm{R}^{2}\right)$ for the Silver-Schmidt was found to be higher than that of the standard Schmidt for both linear and power curve fits. Hence, the Silver-Schmidt results provide relatively better correlation with the compressive strength as shown by both $\mathrm{R}^{2}$ and RMSE values in Table 2.

The base curve provided in EN 13791 [16] is illustrated in Fig. 6. The required shift of the curve was calculated as -5.4 in according with the code relation given by Eq. 1. Coefficient $\mathrm{k}_{1}$ is 1.48 since the number of paired test results in the study is more than 15 .

$$
\Delta f=\delta f_{m(n)}-k_{1} \times s=
$$

Fig. 4. Drilling resistance test 
The relationship between UPV test results and compressive strength is shown in Fig. 8. EN 13791 provides polynomial base curve relation between UPV and compressive strength. Hence, a $2^{\text {nd }}$ order polynomial regression curve was found for UPV $(\mathrm{km} / \mathrm{s})$ vs. compressive strength (MPa). UPV test results show similar correlation with compressive strength for both the polynomial curve and power curve fits.

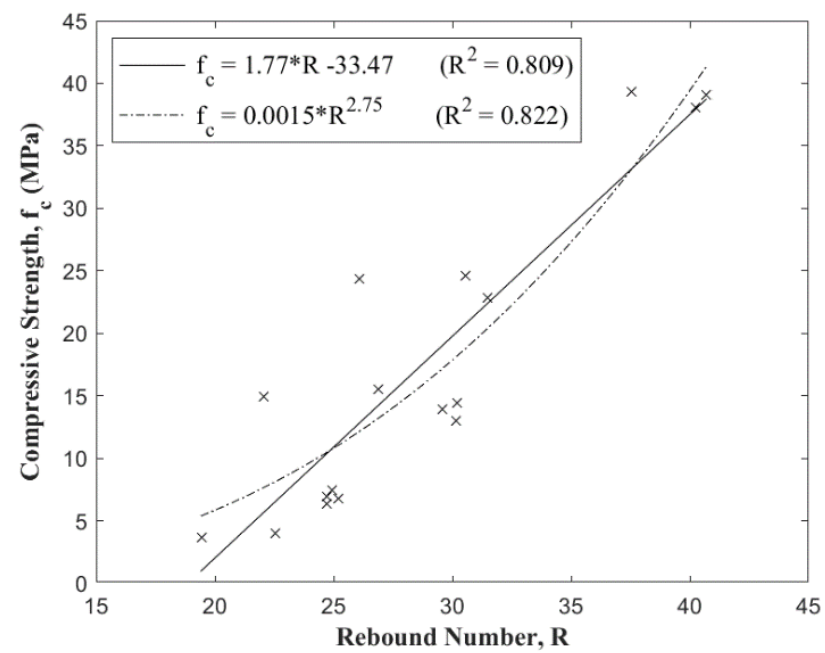

Fig. 5. Correlation between rebound number $(\mathrm{R})$ and compressive strength

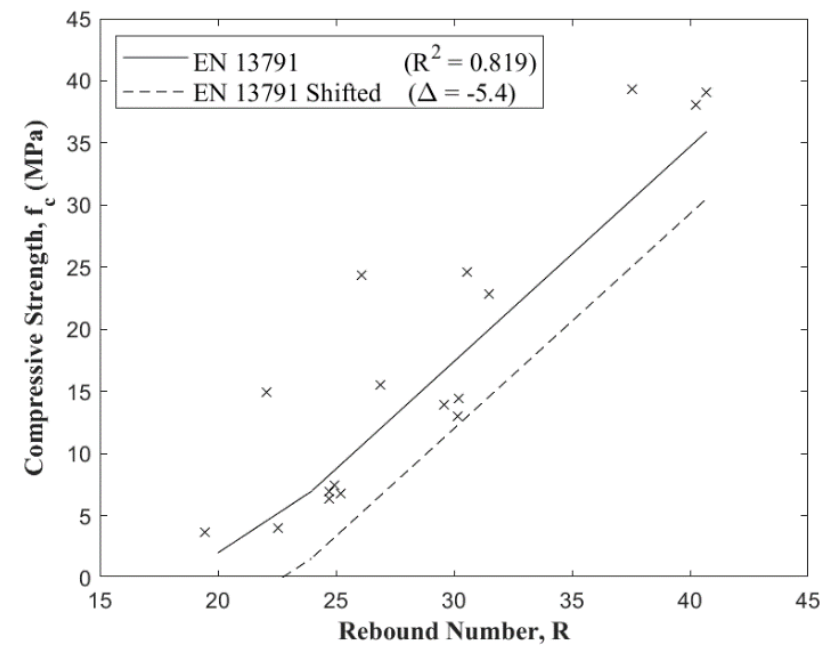

Fig. 6. Basic curve and shifted basic curve for Schmidt hammer (EN 13791)

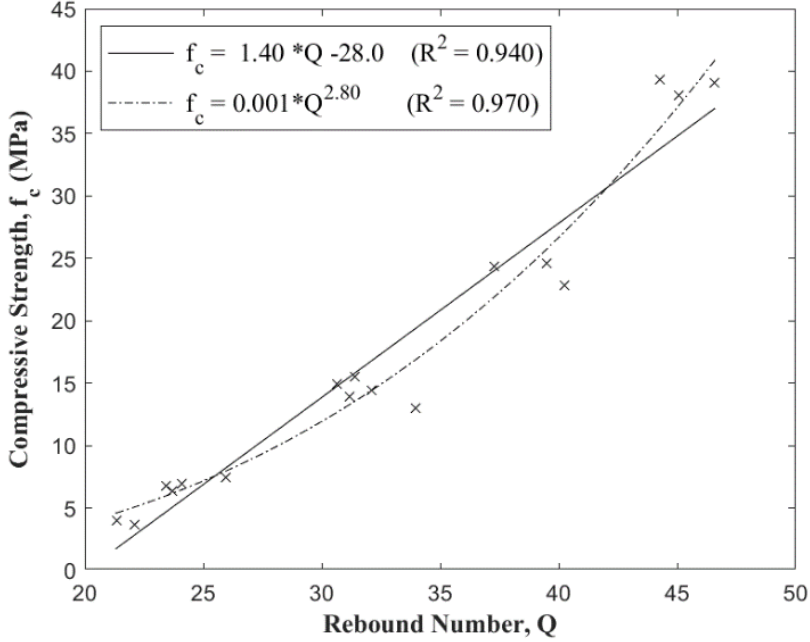

Fig. 7. Correlation between rebound number $(\mathrm{Q})$ and compressive strength

The correlation between UPV and compressive strength is higher than that between standard Schmidt hammer and compressive strength in terms of $\mathrm{R}^{2}$ and RMSE. On the other hand, the Silver-Schmidt provides more reliable strength estimation than all other NDT methods used in this study in terms of $\mathrm{R}^{2}$ and RMSE (Table. 2) .

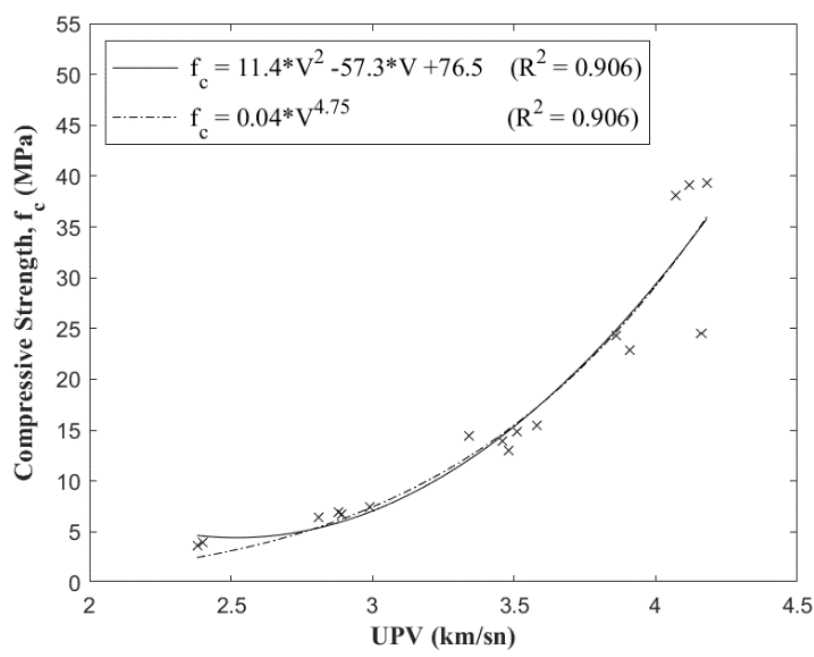

Fig. 8. Correlation between UPV (V) and compressive strength

The relationship between drilling resistance test results and compressive strength test result is shown in Fig. 9. The coefficient of determination for linear and power regression curves are 0.768 and 0.835 , respectively. Furthermore, the RMSE of the power curve fit is about $15 \%$ less than that of the linear regression curve, which are 5,12 and 6,05 $\mathrm{MPa}$, respectively. Consequently, the power curve fit gives a better representation of the relationship between drilling resistance and compressive strength test results. 


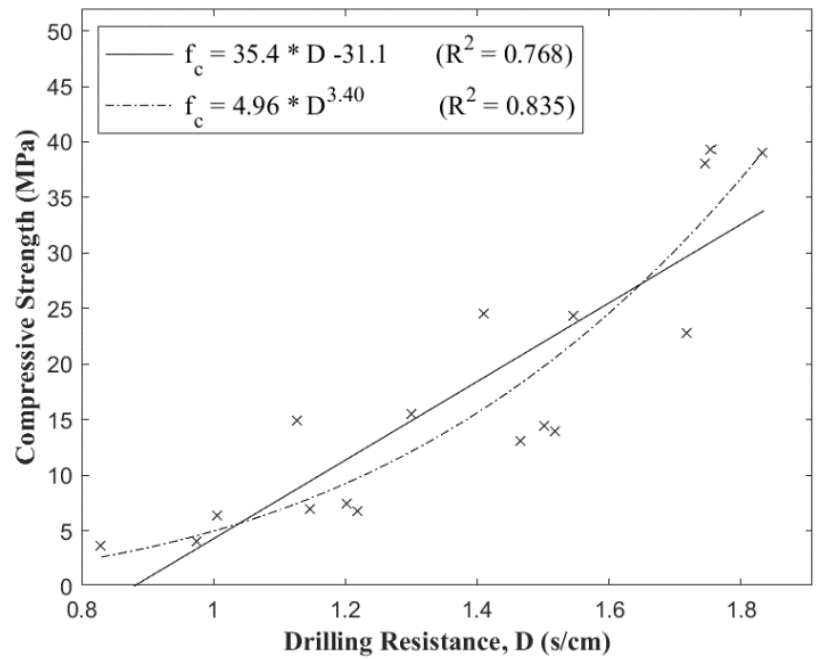

Fig. 9. Correlation between drilling resistance (D) and compressive strength

\subsection{Combined regressions}

Different techniques can be combined to increase accuracy and reliability of concrete strength estimation. Table 3 summarizes regression equations, $\mathrm{R}^{2}$ and RMSE of multivariate regression analyses. Also, these correlations are plotted in Figs 10-14.

Table 3. Relationships between concrete strength and drilling resistance combined with other NDT methods

\begin{tabular}{cccc}
\hline NDT & Equation & $\mathbf{R}^{2}$ & $\begin{array}{c}\text { RMSE } \\
(\mathrm{MPa})\end{array}$ \\
\hline $\mathrm{R}$ & $f_{c}=-34.8+13.5 \times D+1.17 \times R$ & 0.829 & 5.38 \\
$\mathrm{Q}$ & $f_{c}=-29.9+6.3 \times D+1.19 \times Q$ & 0.930 & 3.32 \\
$\mathrm{UPV}$ & $f_{c}=-43.2+13.8 \times D+12.2 \times V$ & 0.845 & 5.12 \\
\hline
\end{tabular}

The relationship between the drilling resistance test - used in combination with both rebound hammer tests - and compression tests are shown in Fig. 10 and Fig. 11. Fig. 12 illustrates the relationship between drilling resistance and UPV combination with compressive strength. Multiple linear regression analyses were performed to obtain the regression curves. As can be seen in Table 3, the drilling resistance and Silver-Schmidt combination gives the best correlation with highest $\mathrm{R}^{2}(0.93)$ and lowest RMSE (2) among all the alternative combinations.

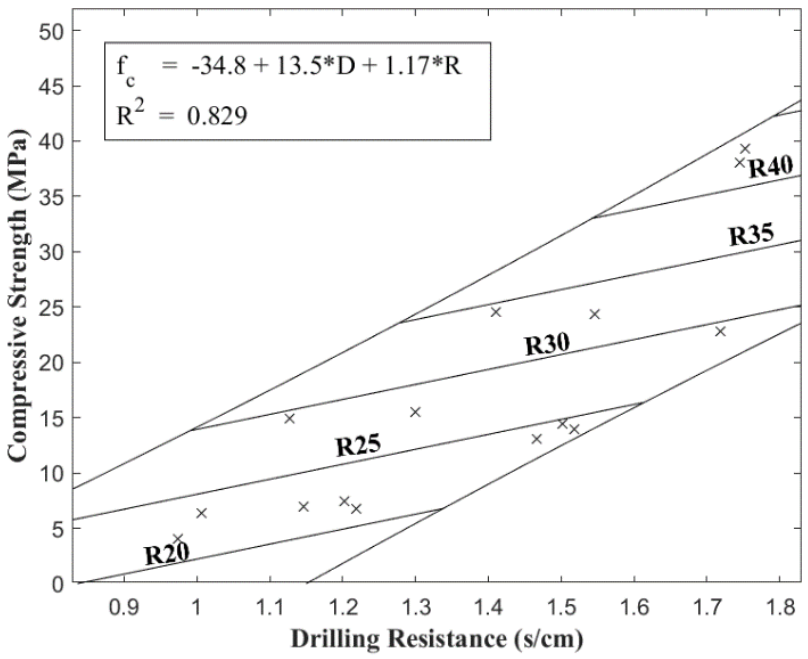

Fig. 10. Combined drilling resistance and rebound number (R) vs compressive strength with $85 \%$ confidence level boundaries

Equations 2 and 3 were derived to estimate concrete strength by combined use of drilling resistance, UPV and standard Schmidt hammer (Eq. 2) or Silver-Schmidt hammer (Eq. 3). $\mathrm{R}^{2}$ of these correlations are 0.912 and 0.947 , respectively.

$$
\begin{aligned}
& f_{c}=-47.5-10.1 \times D+1.2 \times V+12.7 \times R \\
& f_{c}=-20.9-4.9 \times D+1.9 \times V-4.7 \times Q
\end{aligned}
$$

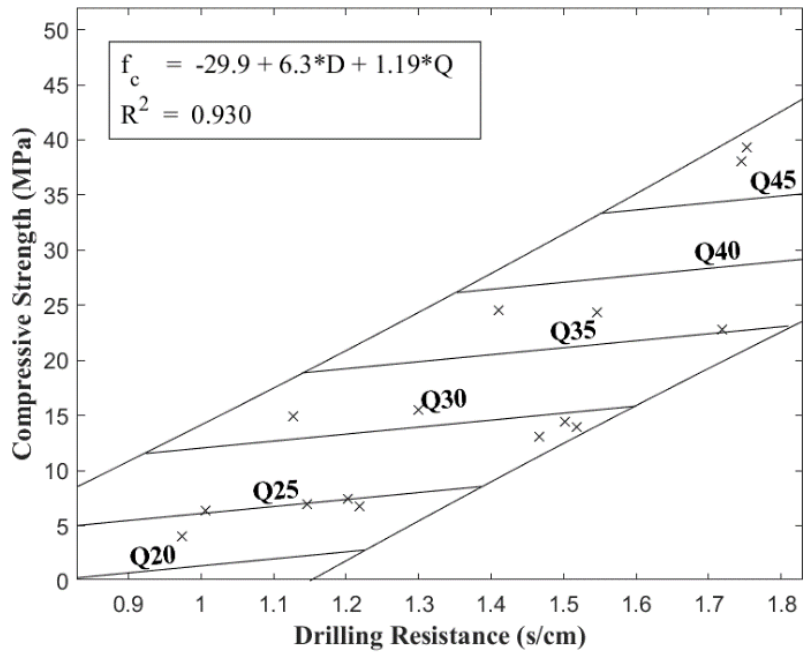

Fig. 11. Combined drilling resistance and rebound number (Q) vs compressive strength with $85 \%$ confidence level boundaries 


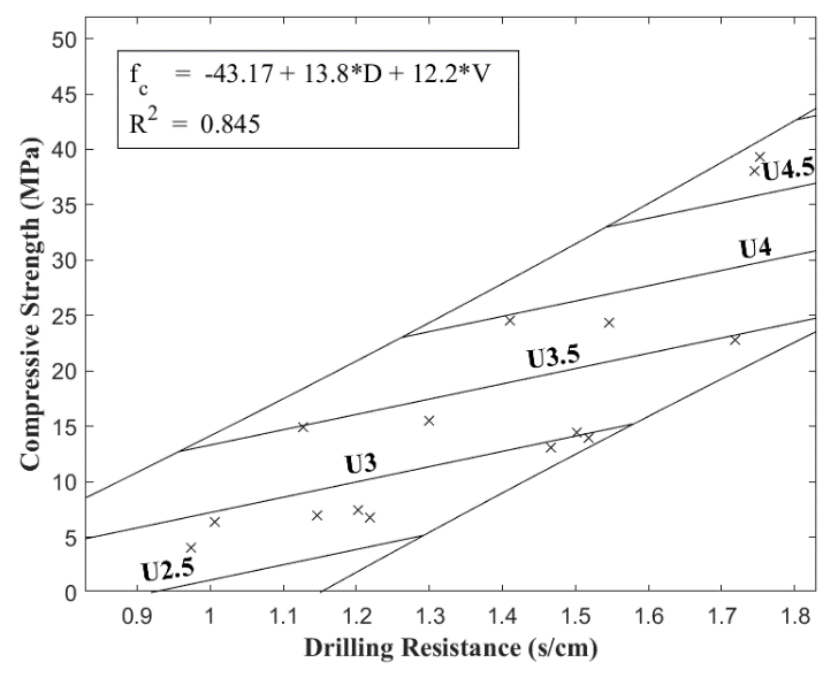

Fig. 12. Combined drilling resistance and UPV (V) vs compressive strength with $85 \%$ confidence level boundaries

\section{Conclusions}

In this paper, the relationship between drilling resistance method and concrete strength, including when it is combined with other NDT methods was investigated and the established correlation curves were reported. Single and multivariate regression analyses were performed for individual and combined use of NDT methods in relation to compressive strength test results. The results reveal that it may be possible to reliably estimate the compressive strength of concrete using drilling resistance method especially when it is combined with Silver-Schmidt hammer. Furthermore, combined use of the drilling resistance method with Schmidt hammer, Silver-Schmidt hammer and UPV methods increased the reliability of concrete strength estimation.

Two equations (Eq.2 and Eq.3) were derived to estimate concrete strength in relation to the combination of 3 NDT methods, namely drilling resistance, UPV, one of two rebound hammer tests. Eq. 2 which involved Silver-Schmidt as rebound hammer shows a relatively better correlation than that involved the standard Schmidt hammer (Eq. 3).

Acknowledgement: The authors gratefully acknowledge the support provided by the Scientific and Technical Research Council of Turkey (TUBITAK) under Project No. 214M054.

\section{References}

1. T. Uomoto, Non-destructive testing in civil engineering, Seiken symposium,26, (2000).

2. Pucinotti, Reinforced concrete structure: Nondestructive in situ strength assessment of concrete, Construction and Building Materials, 75, 331-341, (2015).

3. S. K. Verma, S. S. Bhadauria, S. Akhtar, Review of Nondestructive testing methods, journal of construction engineering, 1,11, (2013).
4. Malhotra VM, Carino NJ. Handbook on nondestructive testing of concrete, ASTM. 2nd ed. CRC Press; 2004.

5. S. P. Pessiki, In-place methods to estimate concrete strength. ACI 228.1R-03 report, (2003).

6. D. Breysse, Non-destructive evaluation of concrete strength: An historical review and a new perspective by combining NDT methods. Construction and Building Materials, 33, 139-163. (2012).

7. EN 12390-3, Testing hardened concrete, Compressive strength of test specimens, CEN, Brussels, (2010).

8. B. Graeye, H. Laar, J. Eijik, W. Gijbels, L. Lauriks, On-site strength assessment of limestone based concrete slabs by combining ndt, J.B.E, 13, 216-223, (2017).

9. EN 12504-2, Testing concrete, determination of rebound number, CEN, Brussels, (2012).

10. D. Corbett, Advancing the rebound hammer method: a new concrete test hammer, Nondestructive Testing of Materials and Structures, Rilem book series $\mathbf{6}$, (2013).

11. M. Breccolotti, M.F. Bonfigli, A.L. Materazzi, Influence of carbonation depth on concrete strength evaluation carried out using the SonReb method, NDT\&E Int.,59,96-104, (2013).

12. EN 12504-4, Testing concrete, determination of ultrasonic pulse velocity, CEN, Brussels, (2004).

13. O. Gunes, Turkey's grand challenge: Disaster-proof building inventory within 20 years. Case Studies in Construction Materials, 2, 18-34, (2015).

14. R. Felicetti, the drilling resistance test for the assessment of fire damaged concrete, Cement \& concrete composites, 28, 321-329, (2006).

15. R. Nogueria, A. P. F. Pinto, A. Gomes, assessing mechanical behaviour and heterogeneity of low strength mortars by the drilling resistance method, Construction and Building Materials, 68, 757-768, (2014).

16. EN 13791, Assessment of in situ compressive strength in structures and precast concrete. CEN, Brussels, (2007). 